\title{
Los datos abiertos y su utilidad en evaluación de políticas públicas y humanidades digitales
}

José Pino-Díaz, Nuria Rodríguez Ortega, Antonio Cruces Rodríguez y Carmen Tenor Polo | Universidad de Málaga, Andalucía Tech, Grupo iArtHis_Lab

URL de la contribución <www.iaph.es/revistaph/index.php/revistaph/article/view/3952>

Las estrategias y políticas públicas actuales, de desarrollo económico y social, apuntan prospectivamente al importante papel que la creación artística, las industrias creativas y las instituciones y entidades culturales juegan en los nuevos modelos productivos, al catalizar generación de riqueza, calidad de vida y bienestar social. Se hace preciso pues que las administraciones y fundaciones públicas, como principales generadoras de políticas públicas culturales, realicen un gran esfuerzo y profundicen en la incorporación del paradigma de los datos abiertos a su modus operandi de difusión y divulgación cultural.

El impulso actual a la evaluación de las políticas públicas culturales se verá de hecho beneficiado con la progresiva incorporación de datos abiertos a sus portales web. La trasparencia en la gestión, puesta de manifiesto con la incorporación de los conjuntos de datos públicos, permitirá la generación de potentes y fiables indicadores para su uso en evaluación, y la toma de decisiones, basada en la evidencia de los datos libres, será más sólida y robusta.

Los conjuntos de datos abiertos presentes en el Portal de datos abiertos del Ayuntamiento de Málaga pueden ser de utilidad en múltiples y variados estudios de carácter social y cultural; por ejemplo, el conjunto de datos de "Equipamientos municipales", en formato CSV, puede ser útil para crear y compartir en la web, con ayuda de Google Maps, un sistema de información sobre equipamientos municipales que integra datos textuales y datos espaciales (PINO-DÍAZ, 2017); o, por ejemplo, el conjunto de datos "Agenda 2017" puede ser de gran utilidad para evaluar la política pública cultural y de ocio, mediante el análisis de la distribución de las actividades por destinatarios, categorías o especialidades, o valo-

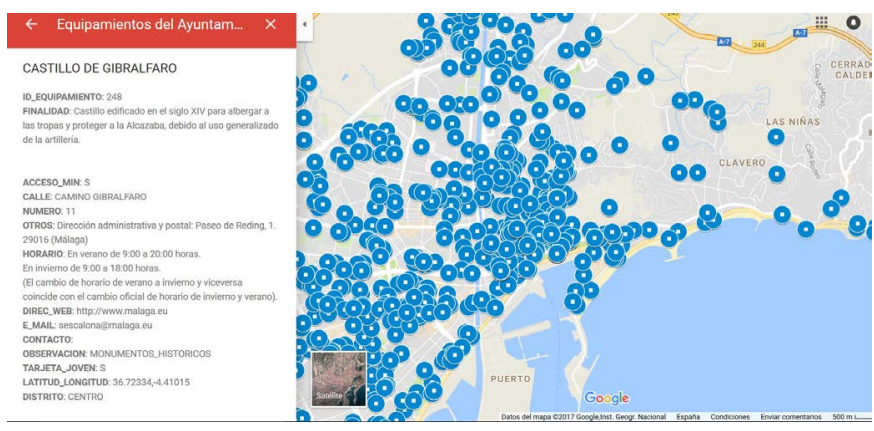

Sistema de información sobre equipamientos municipales de Málaga que integra datos textuales y espaciales. Realizado con datos abiertos y con Google Maps. Compartido en la web | mapa José Pino Díaz

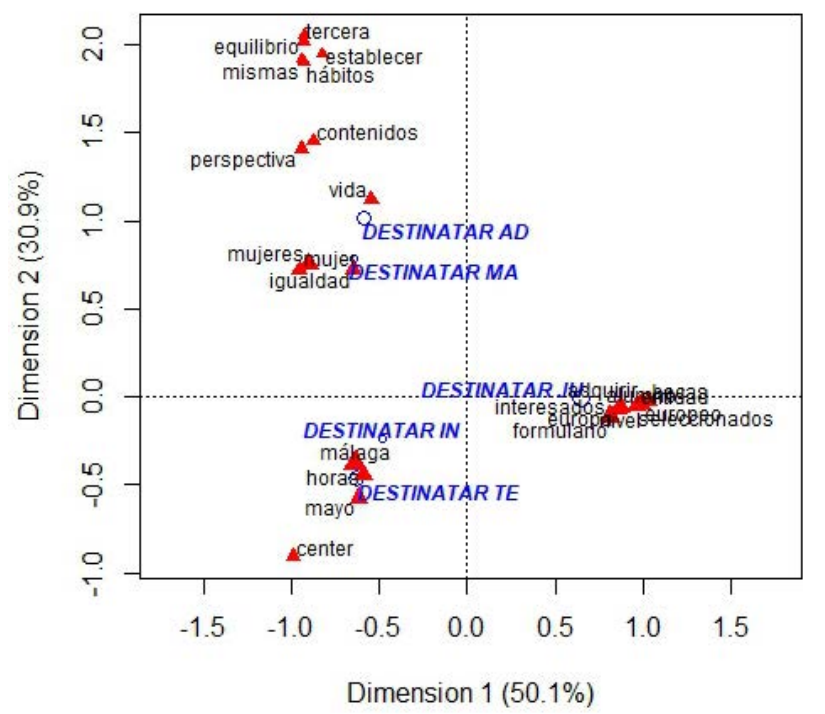

Mapa resultante del análisis factorial de correspondencias realizado con " $R$ Text Mining Solution", R.TeMiS, para analizar la asociación entre el texto de la variable "Descripción de la actividad" y la variable "Destinatarios de la actividad" (TE = todas las edades, I = infantil, JU= Juventud, $\mathrm{AD}=$ adultos y $\mathrm{M}=$ Mayores) $\mid$ mapa José Pino Díaz 
rando el esfuerzo organizador de las diferentes entidades, o también, realizando mediante minería de texto un análisis factorial de correspondencias que asocie las variables descripción del evento y destinatarios.

La investigación aplicada, donde el análisis de datos ocupa un papel primordial, se verá claramente beneficiada del empuje de las administraciones públicas a los datos abiertos. En la actualidad la investigación en humanidades digitales, dada la escasez de datos abiertos culturales, se suple con el desarrollo de algoritmos para la captura de información en la web o con la incorporación manual de esta a bases de datos ad hoc.

En el proyecto de investigación Exhibitium (2014-2016) del grupo de investigación iArtHis_Lab de la Universidad de Málaga, financiado por la Fundación BBVA, para la generación de conocimiento sobre exposiciones artísticas temporales para su reutilización y aprovechamiento multivalente (RODRÍGUEZ-ORTEGA; PINO-DÍAZ; SUÁREZ et ál., 2016), se ha constatado la inexistencia de datos abiertos sobre exposiciones temporales de arte, por lo que se ha debido desarrollar un modelo híbrido "máquina/hombre" basado en un desarrollo tecnológico de recuperación automatizada de información disponible en la web y en su posterior filtrado y grabado manual de la información pertinente en una potente base de datos (CRUCES RODRÍGUEZ; RODRÍGUEZORTEGA; TENOR POLO et ál., 2016).

Dos modestas recomendaciones a los centros de origen de datos, con la finalidad de mejorar la transparencia, favorecer el diálogo entre administraciones públicas y ciudadanos y facilitar la usabilidad de los conjuntos de datos, son: realizar taxonomías más rigurosas y realizar vocabularios controlados para datos textuales en los campos que lo permitan, tales como categorías o especialidades.

\section{BIBLIOGRAFÍA}

- CRUCES RODRÍGUEZ, A.; RODRÍGUEZ-ORTEGA, N.; TENOR POLO, C. et ál. (2016) WordPress as a Framework for Automated Data Capture, Filtering and Structuring Processes. The New Order of the Authors. En Digital Humanities 2016: Conference Abstracts. Kraków: Jagiellonian University \& Pedagogical University, 2016, pp. 469-471

- PINO-DíAZ, J. (2017) Sistema integral de información de equipamientos municipales de Málaga, creado en Google Maps el 10/07/2017 [en línea] <https://drive.google.com/ open?id=1pRJNRyywZ6-j-1CAuQyhnSMwlak\&usp=sharing > [Consulta: 14/07/2017]

- RODRÍGUeZ-ORTEGA, N.; PINO-DÍAZ, J.; SUÁREZ, J. et ál. (2016) Multivalent reuse of web data about temporary art exhibitions: the Exhibitium project. Digital Humanities 2016: Conference Abstracts. Kraków: Jagiellonian University \& Pedagogical University, 2016, pp. 877-879 